\title{
PROCESSO PRIVADO ROMANO: ORALIDADE E ESCRITURA
}

\section{Ricardo Adriano Massara Brasileiro ${ }^{1}$}

\section{RESUMO}

O presente trabalho pretende abordar os modos de apropriação da oralidade e da escritura ao longo dos diversos sistemas processuais de resolução institucionalizada de conflitos privados entre os romanos. Para tanto, abordará a questão no sistema arcaico das legis actiones, bem como no sistema do processo per formulas e, ainda, no sistema processual da cognitio extraordinaria, procurando explicitar os condicionamentos sociais e políticos desses diversos modelos processuais. O texto usa como metodologia a análise de fontes diretas da produção jurídica romana, bem como a pesquisa bibliográfica de natureza histórica, histórico-jurídica e jurídico-processual.

Palavras-chave: Oralidade; Escritura; Processo privado romano.

\section{ROMAN PRIVATE PROCEDURE: ORALITY AND WRITING}

\begin{abstract}
:
The present work intends to deal with the ways of appropriating orality and writing throughout the various procedural systems of institutionalized resolution of private conflicts among the Romans. In order to do so, it will address the issue in the archaic system of the legis actiones, as well as in the per formulas system and also in the procedural system of the extraordinaria cognitio, seeking to make explicit the social and political conditionings of these various procedural models. The paper uses as methodology the analysis of direct sources of Roman legal production, as well as bibliographic research of historical, historical-legal and legalprocedural nature.
\end{abstract}

Keywords: Orality; Writing; Roman private procedure.

\section{INTRODUÇÃO}

O presente trabalho pretende abordar os modos de apropriação da oralidade e da escritura ao longo dos diversos sistemas processuais de resolução institucionalizada de conflitos privados entre os romanos.

Numa perspectiva que se pode chamar de clássica, em consonância com a base material sobre a qual se constrói o discurso processual, tradicionalmente têm sido categorizadas modalidades de sistemas, modelos ou tipos processuais. Assim, é bastante assentada a distinção

\footnotetext{
${ }^{1}$ Doutor e mestre em Direito, Professor do PPGD da Faculdade de Direito Milton Campos, Procurador do Estado de Minas Gerais, Advogado.
} 
entre um sistema processual da oralidade e um sistema processual da escritura. Tais sistemas podem ser identificados quer pela exclusividade do elemento oral ou escrito nas atuações processuais das partes e do magistrado, quer pela prevalência do elemento oral ou do elemento escrito como base material dos atos processuais. ${ }^{2}$ Nesta última hipótese fala-se também de um sistema processual misto.

É certo que com o advento da linguagem informática se deva refletir sobre a existência de um modelo do processo informático. E aqui também é lícito se falar em um processo informático puro, ou num processo notadamente informático, permeado por atos de materialidade oral ou escrita.

O presente texto - que é resultado parcial de uma pesquisa mais ampla, que correlaciona as três modalidades de materialidades discursivas acima relatadas (oralidade, escritura e informática) com matrizes teóricas e modelos processuais concretos e historicamente assentados de processos orais, escritos e informáticos - faz um relevante recorte na extensão da pesquisa possível, direcionando-se diretamente à apreciação das variações entre oralidade e escritura no desenrolar do direito processual romano.

A análise do processo romano se justifica por ter sido uma sua apropriação pela ciência processual da viragem do século XIX para o XX a base para a própria colocação da questão da existência de um modelo processual da oralidade contraposto a um modelo processual da escritura, bem como para a construção dogmática de um marcante princípio processual da oralidade - motriz de muitas reformas processuais subsequentes -, conforme restou demarcado pelos estudos de CHIOVENDA, o mais influente processualista italiano do século XX. ${ }^{3}$

O presente trabalho tem como metodologia escolhida a análise de fontes diretas da produção jurídica romana ${ }^{4}$, bem como a pesquisa bibliográfica de natureza histórica, históricojurídica e jurídico-processual.

\footnotetext{
${ }^{2}$ MILLAR, Robert Wyness. Los principios formativos del procedimento civil. Trad. Catalina Grossman. Buenos Aires: Ediar, 1945, p.144; CHIOVENDA, Giuseppe. Instituições de direito processual civil. v. III. Trad. J. Guimarães Menegale (da 2a ${ }^{\mathrm{a}}$. ed. italiana). São Paulo: Saraiva, 1945, p.68.

${ }^{3}$ A propósito, confira-se: CHIOVENDA, Giuseppe. La idea romana en el proceso civil moderno. In: Ensayos de derecho procesal civil. v. I. Trad. [da ed. italiana de 1930, acrescida de artigos avulsos] Santiago Sentís Melendo. Buenos Aires: EJEA/Bosch, 1949.

${ }^{4}$ Os referenciamentos às ds Institutas de Gaio e de Justiniano podem ser conferidos em: CORREIA, Alexandre e SCIASCIA, GAETANO. Manual de direito romano: Institutas de Gaio e Justiniano vertidas para o português, em confronto com o texto latino. v. II. São Paulo: Saraiva, 1951. Os textos do Digesto, por seu turno, podem-se conferir em: JUSTINIANO. Digesto de Justiniano, liber primus: introdução ao direito romano. Trad. Hélcio Maciel França [edição bilíngüe]. 3 ed. São Paulo: RT; Osasco: UNIFIEO, 2005.
} 


\section{UM TRUÍSMO NECESSÁRIO}

Para começar a exposição, um truísmo deve ser trazido à mente: nas sociedades em que as partes e o juiz não eram alfabetizados, o processo, por certo, deveria ser oral. ${ }^{5}$ Com maior razão, o mesmo se deve dizer das chamadas sociedades de oralidade primária, aquelas anteriores à adoção da escrita. ${ }^{6}$

Estimativas conjecturais recentes, baseadas em comparativos com culturas modernas com recorte civilizatório assemelhado, aquilatam que, durante a república tardia e o principado de Augusto, apenas uma parcela limitada da população - inferior a 15\% da população itálica e inferior a $10 \%$ da população do resto no império - era letrada e capaz de ler e escrever, sendo ainda inferior o número de pessoas com capacidade de leitura de textos literários extensos e complexos. Na época mais antiga é certo que o acesso à leitura era reservado a elites bastante mais restritas. ${ }^{7}$

\section{INTRODUÇÃO DA ESCRITA LATINA}

No ambiente romano, os primeiros sinais da escrita aparecem nos finais dos século VII a.C, com a adaptação e difusão do alfabeto grego já modificado pelos etruscos, sendo que os dois primeiros testemunhos da escrita remontam ao século VI, sendo um deles a inscrição privada num vaso de argila e, a outra, prescrições de caráter religioso, num registro bastante próximo ao alfabeto grego e em sequência bustrofédica, assemelhada ao percurso dos bois ao ararem a terra, de modo à leitura das linhas dever ser realizada de cima para baixo e, depois, de baixo para cima. ${ }^{8}$

É bastante provável que, na época mais arcaica, a exemplo do ocorrido em outras cidades antigas, a escrita tenha se prestado precipuamente ao registro cronológico, religioso,

\footnotetext{
${ }^{5}$ JAUERNIG, Othmar. Direito processual civil. Trad. F. Silveira Ramos [da 25a. ed. alemã, refundida, da obra criada por Friedrich Lent]. Coimbra: Almedina, 2002, p. 153.

${ }^{6}$ LÉVY, Pierre. As tecnologias da inteligência. Tradução de Carlos Irineu da Costa. Rio de Janeiro: Ed. 34, 1993, p. 10 .

${ }^{7}$ Citroni, M., COnSOlino, F. E., LABATE, M., NARdUCCI, E. Literatura de Roma Antiga. Trad. Margarida Miranda e Isaías Hipólito. Rev. trad. Walter de Souza Medeiros. Lisboa: Fundação Calouste Gulbenkian, 2006, p. 16-17.

${ }^{8}$ Citroni, M., CONSOlinO, F. E., LABATE, M., NARDUCCI, E. Literatura de Roma Antiga. Trad. Margarida Miranda e Isaías Hipólito. Rev. trad. Walter de Souza Medeiros. Lisboa: Fundação Calouste Gulbenkian, 2006, p. 39.
} 
contabilístico ou administrativo, sendo considerada monopólio dos agentes afetos a tais atividades. ${ }^{9}$

\section{ATIVIDADE PONTIFICIAL}

A escrita era uma atividade particularmente importante do colégio de pontífices, que eram, desde tempo muito remotos, os depositários, guardiões e intérpretes da memória coletiva, acumulada ao longo de gerações. Eram eles os detentores de das sequencias formulares utilizadas em preces e invocações rituais das divindades, utilizadas em muitos atos públicos relevantes, como também detentores das fórmulas necessárias para a o uso da justiça pelo cidadão, além de exercerem o controle do tempo para fins sociais, com a previsão das luas e dos dias em que eram permitidas (dies fasti) ou proibidas (dies nefasti) pela religião a pronúncia (fari, donde, provavelmente, fastus) das fórmulas rituais para a realização das ações públicas e para a administração da justiça. ${ }^{10}$

O saber pontificial tinha, na origem, acentuado caráter mágico-religioso e se apresentava na forma tipicamente oracular da resposta (responsum) a consultas sobre qual a conduta verbal e gestual a ser adotada em determinadas situações social ou privadamente relevantes, tais como, num primeiro momento, a elaboração de um testamento, a alienação ou aquisição de bens, a regulação de parentescos em razão de falecimentos ou casamentos, situações estas de particular interesse das classes mais abastadas, bem como, com a complexificação das relações sociais, a outros aspectos de interesse da vida coletiva, com progressivo arrefecimento do caráter sacerdotal das respostas, sem o abandono, contudo, da propensão da codificação do responso oral em formulações breves, de fácil memorização e forte componente rítmico - daqui o caráter marcadamente formular do antigo direito romano. ${ }^{11}$ No entanto, a reivindicação de assemelhamento da atividade dos juristas à atividade de sacerdotes que cultuam a justiça e professam o conhecimento do bom e do justo, bem como a reivindicação de enquadramento do saber jurídico (iurisprudentia) ao conhecimento das coisas divinas e humanas (divinarum atque humanorum rerum notitia), com a ciência do justo e do

\footnotetext{
${ }^{9}$ Citroni, M., COnsolino, F. E., LABAte, M., NARDUCCI, E. Literatura de Roma Antiga. Trad. Margarida Miranda e Isaías Hipólito. Rev. trad. Walter de Souza Medeiros. Lisboa: Fundação Calouste Gulbenkian, 2006, p. 39-40.

${ }^{10}$ Citroni, M., CONSOlino, F. E., LABATE, M., NARDUCCI, E. Literatura de Roma Antiga. Trad. Margarida Miranda e Isaías Hipólito. Rev. trad. Walter de Souza Medeiros. Lisboa: Fundação Calouste Gulbenkian, 2006, p. 40-41

${ }^{11}$ Citroni, M., CONSOlino, F. E., LABATE, M., NARDUCCI, E. Literatura de Roma Antiga. Trad. Margarida Miranda e Isaías Hipólito. Rev. trad. Walter de Souza Medeiros. Lisboa: Fundação Calouste Gulbenkian, 2006, p. 41-42.
} 
injusto (justi atque injusti scientia), ressoam ainda na época de Justiniano (séc. VI), catorze séculos depois à lendária fundação de Roma (753 a. C), tanto pela a reprodução de excerto de ULPIANO no Digesto (D. 1.1.1.1 - o texto originário de ULPIANO é do século III), como pela concepção exposta nas Institutas (I. 1.1.1), que foram elaboradas com claro desígnio manualístico de formação educacional e dedicadas à juventude desejosa de estudar as leis (cupidae legum juventuti - Proemium).

Os próprios termos que designam tais sacerdotes em latim - pontifex, pontificis parecem encerrar uma história curiosa. O relacionamento etimológico com pons e facio remontam a uma suposição antiga de que os pontífices foram os primeiros construtores de uma ponte sobre o Tibre para a prática de um culto do outro lado do rio. ${ }^{12}$ Era o pontífice quem deveria manter a ordem de uma natureza concebida como fervilhante de espíritos, aplacando “as náiades da água violada pela ponte", restabelecendo "a harmonia de uma natureza em que o homem uniu as duas margens que a divindade queria divididas"; mas era também o pontífice o técnico da engenharia civil de uma sociedade primitiva, depositário dos próprios conhecimentos que facultavam o robustecimento econômico da sociedade. ${ }^{13} \mathrm{O}$ Tibre constituía um eixo fluvial de grande importância para a comunicação e o intercâmbio com o resto da Itália, e a conformação física das colinas romanas beneficiava o direcionamento dos interesses dos habitantes ao rio, sendo bastante provável que a possibilidade de controle do tráfego comercial foi o que outorgou a Roma uma posição de vantagem relativamente às comunidades fronteiriças, direcionando a um tendencial deslocamento do eixo econômico da cidade de uma matriz agrícola e pastoril a uma matriz comercial. ${ }^{14}$

\section{SISTEMAS PROCESSUAIS ROMANOS}

No contexto da grande institucionalização do direito entre os romanos, a ação judicial, ou seja, "a atuação endereçada a resolver uma controvérsia mediante uma decisão definitiva (iudicatum) fundada na opinião de um juiz privado (sententia)" - é a atuação mais institucionalizada; a ação romana é o ato jurídico por excelência. ${ }^{15}$

\footnotetext{
${ }^{12}$ Dicionário de latim-português. 2 ed. Porto: Porto Editora, 2001, p. 522 - não há indicação de autoria.

${ }^{13}$ LOSANO, Mario G. Os grandes sistemas jurídicos: introdução aos sistemas europeus e extra-europeus. Trad. Marcela Varejão. Rev. trad. Silvana Cobucci Leite. São Paulo: Martins Fontes, 2007, p. 32

${ }^{14}$ Citroni, M., CONSOlinO, F. E., LABATE, M., NARDUCCI, E. Literatura de Roma Antiga. Trad. Margarida Miranda e Isaías Hipólito. Rev. trad. Walter de Souza Medeiros. Lisboa: Fundação Calouste Gulbenkian, 2006, p. 37.

${ }^{15}$ D'ORS, Alvaro. Derecho privado romano. 10 ed. Pamplona: EUNSA, 2004, p. 121, de quem o trecho reproduzido entre aspas.
} 
O desenrolar do direito romano conheceu três sistemas processuais que tiveram algum convívio simultâneo, mas que findaram por se suceder reciprocamente: (1) o sistema arcaico das legis actiones, (2) o menos formal sistema do processo formular, também conhecido como processo clássico, surgido em meados do século II a.C. e tornado a regra geral em fins do século I a.C., e (3) o sistema da cognitio extraordinaria, que conviveu com o processo clássico para situações específicas e findou por tornar-se o processo comum, com Diocleciano (fins do século II e início do século III d.C.), até a abolição formal do processo formular, no ano de 342. ${ }^{16}$ Para além de distinções de ordem técnica, tais sistemas processuais refletem cenários bastante diferenciados da história romana, tanto no aspecto jurídico, como nos aspectos antropológico e político ${ }^{17}$, o que se procurará abordar ao longo da exposição.

Nos dois primeiros sistemas, que ficaram posteriormente conhecidos como integrantes da ordo judiciorum privatorum, a estrutura do processo cognitivo é bipartida, havendo uma primeira fase de oitiva preliminar das partes e admissão do litígio, chamada fase in iure, desenvolvida perante um magistrado judicial, num tribunal, e uma posterior fase, em que produzidas as provas e prolatada a sentença, chamada fase apud iudicem ou in iudicio, desenvolvida junto a um juiz privado (iudex unus) ou junto ao colégio de juízes privados (recuperatores), a quem foi confiada a função judicial.

Nesses sistemas processuais, os juízos relativos ao ius são juízos privados, tanto em razão da matéria, como, sobretudo, pela condição privada das partes e do juiz, que não é magistrado, nem um servidor, mas um particular encarregado do juízo (iudex privatus). Desse modo, os iudicia privata se distinguem dos juízos públicos, como, por exemplo, os juízos criminais e políticos. ${ }^{18}$

\section{SISTEMA DAS LEGIS ACTIONES}

O processo romano arcaico das legis actiones é um modelo histórico de processo oral puro, reservado aos cidadãos romanos, que prestava-se a tutelar o velho núcleo tradicional do direito, o ius civile, assentado em costumes com dignidade religiosa ${ }^{19}$ e, posteriormente, nas já escritas XII Tábuas. As atuações processuais in iure consistiam na observações escrupulosa de

\footnotetext{
${ }^{16}$ CORRÊA, Alexandre; SCIASCIA, Gaetano. Manual de direito romano. 6 ed. São Paulo: RT, 1988, p. 76-91, §§ 40-49

${ }^{17}$ STOLFI, Emanuele. Il processo civile. In: SCHIAVONE, Aldo. Diritto privato romano: un profile storico. 2 ed. [s/l]: Einaudi, 2010, p. 79.

${ }^{18}$ D'ORS, Alvaro. Derecho privado romano. 10 ed. Pamplona: EUNSA, 2004, p. 122-123, § 70, onde referenciado todo o conteúdo do parágrafo.

${ }^{19}$ CLAVERO, Bartolome. Institucion historica del derecho. Madrid: Marcial Pons, 1992, p. 21.
} 
ritos e de determinados gestos e formas orais, performados diante do próprio rei ou dos primeiros magistrados republicanos, perante os quais se deveriam fazer presentes as próprias partes e o bem disputado. Eram pouquíssimas as ações judiciais admitidas, usualmente descritas em número de cinco (três cognitórias e duas executivas), número este talvez adequado para a tutela dos limitados direitos afetos a uma pequena comunidade rural, participante dos mesmos cultos. Tal processo era marcado por um formalismo ritual e sacramental bastante acentuado, numa inextrincável combinação de elementos religiosos e jurídicos. Uma mínima omissão ou um erro resultariam na perda da demanda. Assim como na prática dos cultos e nas experiências de magia, somente a reprodução fidelíssima do gesto e da palavra poderiam produzir efeitos com validade. ${ }^{20}$

GAIO, em texto posto no século II (Institutas, 4, 11, e 4, 30), assim se expressa:

11. As acções usadas dos antigos chamavam-se acções da lei, seja de se originarem das leis (pois no tempo não existiam ainda os editos do pretor, introductórios de várias acções), seja por se conformarem às palavras das próprias leis, conservando-se por isso imutáveis como as leis mesmas. Dai o ter-se respondido que perdia a acção quem, agindo por causa de videiras cortadas, mencionava videiras, pois a lei das XII Tábuas, na qual se fundava a acção por videiras cortadas, falava de árvores cortadas em geral. [...] 30. Mas tôdas estas acções da lei tornaram-se a pouco e pouco odiosas. Pois, dada a extrema sutileza dos antigos fundadores do direito, chegou-se à situação de, quem cometesse o menor êrro, perder a causa.

A título de exemplificação, veja-se a ritualidade de uma das mais antigas ações da lei, a ação da lei por aposta sacramental (legis actio sacramento in rem), uma ação cognitiva em que o autor buscava apoderar-se de coisa tida como própria e se discutiam direitos de domínio. Nesta ação, GAIO $(4,16)$ sustenta que o autor da demanda deveria aportar a coisa vindicada a juízo (se móvel ou semovente, por exemplo, um escravo) e reclamá-la, empunhando a varinha, do seguinte modo:

"EU DIGO QUE ESTE HOMEM É MEU POR DIREITO DOS QUIRITES, SEGUNDO SUA SITUAÇÃO JURÍDICA ["AIO SECUNDUM CAUSAM SUAM"]. ASSIM COMO DISSE, VÊ, Ó TU, TOQUEI-O COM A VARINHA; e ao mesmo tempo tocava o escravo com ela."

Querendo o réu opor-se, prossegue GAIO:

"o adversário dizia e fazia o mesmo. Quando as duas partes tinham vindicado, o pretor dizia: LARGUEM, AMBOS O ESCRAVO, e eles largavam. O primeiro vindicante interrogava o outro assim: PEÇO DIGAS A QUE TÍTULO VINDICASTE; e o

\footnotetext{
${ }^{20}$ Para o geral do parágrafo: STOLFI, Emanuele. Il processo civile. In: SCHIAVONE, Aldo. Diritto privato romano: un profile storico. 2 ed. [s/1]: Einaudi, 2010, p. 79 e 85. Em menor extensão: CLAVERO, Bartolome. Institucion historica del derecho. Madrid: Marcial Pons, 1992, p. 21.
} 
segundo respondia: EXERVI MEU DIREITO TOCANDO COM A VARINHA. Em seguida, o primeiro vidicante dizia: VISTO TERES VINDICADO INJUSTAMENTE, DESAFIO-TE A UM SACRAMENTUM DE QUINHENTOS ASSES, o adversário dizia também o mesmo: E EU TE DESAFIO A TI. [...]

O toque da varinha (inpositio festucae) valia pela representação simbólica do justo domínio, dado que estava no lugar da lança de guerra (GAIO, 4, 16), num contexto histórico em que a conquista bélica era o mais firme título de propriedade. ${ }^{21}$

Se a coisa fosse imóvel ou de difícil transporte, era necessária a apresentação de parte dela em juízo. Assim, de um rebanho, deveria aportar-se uma ovelha ou uma cabra ou mesmo um pouco de pelo desses animais; de um fundo, um punhado de terra; de um edifício, uma telha, e assim por diante. (GAIO, 14, 17)

Na pré-história dessa ação da lei, a totalidade do procedimento transcorre possivelmente perante o próprio rei, provavelmente coadjuvado por um colégio pontificial. ${ }^{22}$ E o sacramentum equivale, em certos casos, a um juramento no qual as partes pretendiam reforçar as suas afirmações, com um ato de auto-amaldiçoamento condicional, para a hipótese de não ser verdadeiro o conteúdo do jurado. Daí o necessário depósito de uma quantia expiatória, a ser entregue à divindade ou ao tesouro do templo a fim de remir o perjúrio, no caso de perda da demanda. Num estágio mais avançado, a perda do sacramento, então já considerado como uma aposta, era feita em benefício do tesouro público, como pena processual. ${ }^{23} \mathrm{~A}$ conformidade dos juramentos contrapostos ao ius era provavelmente aferida por critérios estritamente religiosos, próximos aos "juízos de deus", como voos de pássaros ou o exame de vísceras de animais sacrificados, o que foi sendo progressivamente substituído pela prática testemunhal, na medida da maior laicização e racionalização do procedimento, agora já bipartido, com o acometimento da produção probatória a um juiz privado, talvez sob o modelo de uma mais moderna ação da lei, a legis actio per iudicis arbitrive postulationem, derivada das XII Tábuas. ${ }^{24}$

A outra mais antiga ação da lei, a manus iniectio, era uma ação de execução pessoal que se prestava para o apoderamento do corpo do devedor que não pagava. Nela, o exequente põe a mão sobre o devedor, diante do magistrado, com uma fórmula verbal ritual fixa, adquirindo,

\footnotetext{
${ }^{21}$ PUGLIESE, Giovanni, con la collaborazione di SITZIA, Francesco, e VACCA, Letizia. Istituzioni di dirito romano. 3 ed. Torino: Giappichelli, 1991, p. 69, § 29.1 III.

22 STOLFI, Emanuele. Il processo civile. In: SCHIAVONE, Aldo. Diritto privato romano: un profile storico. 2 ed. [s/1]: Einaudi, 2010, p. 97-98.

${ }^{23}$ KASER, Max. Direito privado romano. Trad. [da edição alemã de 1992] Samuel Rodrigues e Ferdinand Hämmerle. Lisboa: Calouste Gulbenkian, 1999, p. 436, § 81 II 1 c.

${ }^{24}$ STOLFI, Emanuele. Il processo civile. In: SCHIAVONE, Aldo. Diritto privato romano: un profile storico. 2 ed. [s/1]: Einaudi, 2010, p. 79.
} 
assim, poder sobre a sua pessoa. Na eventualidade de o devedor não ser desobrigado em tempo hábil, em conformidade com as XII Tábuas, pode ser morto ou vendido como escravo, consequências estas que foram posteriormente atenuadas. ${ }^{25}$ Tome-se o expressivo relato de $\operatorname{GAIO}(4,21)$ :

21. Agia-se também por manus iniectio no caso de alguma lei assim o determinar; como na ação de coisa julgada, de acordo com a lei das XII Tábuas. Nesta ação se procedia assim. O autor dizia: VISTO NÃO ME HAVERES PAGO OS DEZ MIL SESTÉRCIOS, A QUE FOSTE CONDENADO A PAGAR-ME, EU LANÇO A MÃO SOBRE TI, POR CAUSA DOS DES MIL SESTÉRCIOS; ao mesmo tempo pegava uma parte qualquer do corpo do devedor. Nem era permitido ao condenado repelir a mão que o prendia e agir pessoalmente, mas nomeava um representante (vindex), para agir por ele; quem não tivesse representante era levado à casa do autor e posto a ferros.

O devedor viveria à sua própria custa, se quisesse. Se não quisesse, o credor lhe daria, no mínimo, uma libra de farinha por dia, durante o prazo de 60 dias em que o credor podia mantê-lo acorrentado ou amarrado, pelos pé e pescoço, com peso não superior a 15 libras. Inexistindo o resgate, o credor o levaria em três dias consecutivos de feira diante do pretor e apregoaria publicamente o valor da dívida. Não comparecendo quem o remitisse, poderia ser vendido além do Tibre, ao estrangeiro, ou morto pelo credor. Havendo vários credores, o corpo do devedor poderia ser dividido em tantos pedaços quantos fossem os titulares do crédito, não importando cortar mais ou menos. Essa repartição do cadáver do devedor, tinha a provável função de propiciar aos credores a faculdade de forçar os parentes do morto ao pagamento da dívida, a fim de não incidirem em sanções sacrais por insepultura. ${ }^{26}$

\section{PROCESSO FORMULAR}

O processo formular tem sua origem provavelmente vinculada à expansão territorial romana e à necessária resolução de conflitos havidos entre estrangeiros ocupantes do território, a quem vedadas as velhas fórmulas, e entre estrangeiros e cidadãos romanos. Deriva, enfim, da relação com outros povos em função do comércio mediterrâneo, no qual Roma passou a se inserir a partir da primeira idade republicana e que passou a controlar após a vitória sobre Cartago. Essa modalidade processual é já acessível a estrangeiros e assume um caráter mais

\footnotetext{
${ }^{25}$ KASER, Max. Direito privado romano. Trad. [da edição alemã de 1992] Samuel Rodrigues e Ferdinand Hämmerle. Lisboa: Calouste Gulbenkian, 1999, p. 437-438, § 81 III 1.

${ }^{26}$ KASER, Max. Direito privado romano. Trad. [da edição alemã de 1992] Samuel Rodrigues e Ferdinand Hämmerle. Lisboa: Calouste Gulbenkian, 1999, p. 438, § 81 III 1; MEIRA, Sílvio A. B. A lei das XII tábuas: fonte do direito público e privado. 3 ed. Rio de Janeiro: Forense, 1972, p 169.
} 
laico e já é ligado a elementos escritos (a saber, o texto normativo de referência, previsto no édito pretório anual, e a fórmula) e a técnicas menos arcaicas e pretensamente mais racionais de investigação probatória, bem como reflete uma nova visão sobre o direito: distinto da religião, não confinado às dimensões da cidade, aberto à vontade das partes, que já libertas das exigências rituais para a livre exposição das suas pretensões ao magistrado, sem limitações rituais. O processo é dependente do impulso das partes e dominado pela presença dos magistrados, dotados de iurisdictio, ao redor que quem figuravam os juristas que lhe aconselhavam ou que lhe comentavam o édito, em que eram indicados os meios de tutela assegurados às partes. Tais protagonistas, magistrados e juristas, são propriamente os agentes que orientam o inteiro o desenvolvimento do direito nos últimos séculos da república. ${ }^{27}$

Esse novo sistema processual permitiu uma eclosão de novas fórmulas, com substancial ampliação dos direitos tuteláveis. ${ }^{28}$ Tais novas fórmulas constavam do álbum do pretor (édito), que era um político e que revelava quais os direitos admitiria previamente durante o período de sua magistratura. Mas podiam ser adaptadas às exigências de novas causas, em geral por obra de juristas consultados pelas partes, e assim submetidas à apreciação do magistrado.

Após a respectiva admissão, a fórmula era remetida de forma escrita ao juiz ou colégio de juízes, contendo um resumo dos termos fundamentais da lide, estando fixado o programa do futuro juízo sobre o mérito da causa. A fórmula continha a estrutura básica de um juízo hipotético alternativo, com determinação ao juiz de resolução do caso segundo um raciocínio pré-moldado do seguinte tipo: acaso comprovada (si paret) a concretude fática de determinadas premissas enunciadas no corpo formular, o juiz deveria estabelecer conseqüências jurídicas desfavoráveis ao réu e benéficas ao autor, conseqüências estas também enunciadas no texto da fórmula. No caso contrário, acaso não verificadas (si non paret) as premissas deduzidas, competia ao juiz absolver o réu. ${ }^{29} \mathrm{Em}$ suma, si paret ... condemna, si non paret ... absolve, tal como se pode observar dos dois exemplos de fórmula abaixo:

(1) SE PARECER QUE N. N. DEVE DAR X MIL SESTÉRCIOS A A. A., JUIZ, CONDENA N. N. A PAGAR DEZ MIL SESTÉRCIOS A A. A.; SE NÃO PARECER QUE N. N. DEVE PAGAR, ABSOLVE. (GAIO, Institutas, 4,41 e 4,43)

\footnotetext{
${ }^{27}$ Parta todo o conteúdo do parágrafo: STOLFI, Emanuele. Il processo civile. In: SCHIAVONE, Aldo. Diritto privato romano: un profile storico. 2 ed. [s/l]: Einaudi, 2010, p. 79-80.

${ }^{28}$ VILLEY, Michel. Direito romano. Trad. Fernando Couto. Porto: Rés [s.d], p. 58-60.

${ }^{29}$ BETTI, Emilio. Processo civile: diritto romano. In: AZARA, Antonio e EULA, Ernesto (Dir.). Novissimo digesto italiano. v. XIII. Torino: Utet, 1966, p. 1.109, col. 2/1.110, col. 1, § 14.
} 
(2) SE SE PROVA QUE N. N. DEVE DAR AO AA 100 MÓDIOS DE TRIGO DE TIPO AFRICANO DE PRIMEIRA QUALIDADE, CONDENA, JUIZ, N. N. A FAVOR DE A. A. NA SOMA DE DINHEIRO QUE CORRESPONDE AO VALOR ACTUAL DO DITO OBJECTO, SE NÃO SE PROVA, ABSOLVE-O. ${ }^{30}$

Nos formulários processuais, as abreviaturas convencionais A. A. e N. N. referenciam, respectivamente, demandante e demandado e revelam uma pequena ironia que os caricatura como "rico exigente" (Aulus Agerius) e "pobre insolvente" (Numerius Negidius). ${ }^{31}$ Por certo, contudo, num litígio concreto, os nomes hipotéticos eram substituídos pelos nomes reais do demandante e do demandado, bem como se fazia anteceder à fórmula a indicação do nome do juiz ou juízes eleitos que cumpririam a determinação do magistrado: "Titius iudex esto" ou "Titius, Caius, Marcus, etc., recuperatores sunto". ${ }^{32}$ A título de mais uma exemplificação:

(3) FULANO, SÊ JUIZ. VISTO QUE A. A. DEPOSITOU JUNTO A N. N. UMA MESA DE PRATA, OBJETO DESTA AÇÃO, CONDENA N. N. EM FAVOR DE A. A. NAQUILO QUE, POR CAUSA DE DEPÓSITO N. N. DEVE DAR OU FAZER EM BOA FÉ, A NÃO SER QUE RESTITUA A MESA. SE NÃO PARECER QUE N. N. DEVE DAR OU FAZER, ABSOLVE. (GAIO. 4, 47).

Nos princípios do processo formular, supõe-se que o decreto que fixava a fórmula não se representava por escrito, mas se comprovava ao juiz por via testemunhal. Posteriormente, o programa do processo e a ordem de julgamento direcionada ao juiz já se documentavam em tabuinhas, na forma comum aos documentos com testemunhas (testationes). Tratava-se de tabuletas de madeira cobertas de cera ou de uma resina vegetal (tabulae ceratae), que eram superpostas, atadas com cordéis por perfurações laterais e seladas nas extremidades das amarras pelas partes e pelas testemunhas formando assim um documento escrito em duplicata, com uma face exposta e outra oculta, de modo a se evitarem adulterações do texto. No momento da apresentação do documento in iudicio, as testemunhas se apresentavam e, se necessário, reconheciam seus selos antes dos respectivos rompimentos. Nas tábuas se escrevia com um estilo (stilus) e se apagava com uma espátula ligeiramente aquecida, às vezes consistente de uma extremidade chata do próprio instrumento de riscadura. Ao que parece, as limitações tecnológicas à escrita contribuíram para a necessária concisão do texto formular -

\footnotetext{
${ }^{30}$ Exemplo extraído de KASER, Max. Direito privado romano. Trad. [da edição alemã de 1992] Samuel Rodrigues e Ferdinand Hämmerle. Lisboa: Calouste Gulbenkian, 1999, p. 482, anexo, que se referencia ao dito no $\S 83$ II 2.

${ }^{31}$ D'ORS, Alvaro. Derecho privado romano. 10 ed. Pamplona: EUNSA, 2004, p. 128, § 75. Para uma especulação sobre a origem desses nomes, com indicação de múltiplas fontes: BRASILEIRO, Ricardo Adriano Massara. $O$ objeto do processo civil clássico romano. Belo Horizonte: Líder, 2007, p. 112.

${ }^{32}$ D'ORS, Alvaro. Derecho privado romano. 10 ed. Pamplona: EUNSA, 2004, p. 122, § 69.
} 
atributo este que findou como apanágio de todo o estilo jurídico romano - e para a correlata maior abertura semântica do registro, que ou deixava in albis a origem do dever jurídico em persecução judicial (fórmulas certas - exemplos 1 e 2 , acima) ou não circunscrevia pormenorizadamente o próprio conteúdo da pretensão deduzida (fórmulas incertas - exemplo 3, acima), possibilitando, assim, alguma margem à apreciação judicial. ${ }^{33}$

No processo formular há grande contato direto das partes tanto com o pretor como com o juiz. Todos os atos postulatórios são orais. São igualmente orais todas as atuações in iudicio das partes. No processo formular vige, com maior plenitude, o princípio da liberdade do juiz na interpretação das provas, mas em compensação, o juiz deve ater-se às provas apresentadas, não podendo inquirir outras. Para a administração e interpretação das provas intervêm a retórica e a eloquência dos advogados. Inexistem regras fixas para os ônus probatórios, cabendo, geralmente, ao autor a comprovação dos fatos que fundamentam sua pretensão e, ao réu, os relativos à sua exceptio. Valem como prova as declarações das partes (juramentos e confissões) ou de testemunhas (testes) e documentos (instrumenta), sendo característica do processo clássico a preferência pelas testemunhas, o que não impediu os instrumenta de irem ganhando maior importância ao longo do tempo. ${ }^{34}$ Valem igualmente como prova quaisquer meios aptos a fundamentar a decisão, de modo a serem ocasionalmente utilizadas a inspeção e a oitiva de peritos (v.g., parteiras sobre uma gravidez; agrimensores). A apresentação das provas compete às partes, e não ao juiz, que, como aludido, as pode apreciar livremente. ${ }^{35}$ Inexistem presunções legais, consistentes em dispensa de prova, mas, sim, algumas regras de interpretação ( $v . g$, paternidade pelo convívio marital) que se converteram na época pós-clássica em presunções. ${ }^{36}$

São precisamente algumas dessas características acima apontadas mais do que a integralidade da produção dos atos processuais na forma oral, aquilo que a dogmática processual moderna consolidou como o característico do processo oral. A categorização primordial da oralidade elaborada por CHIOVENDA é tributária da correlação que o autor fez entre função da prova e forma do processo, no sentido de que, segundo entendeu, "um processo dominado pelo princípio da livre convicção do juiz, e que queira realizar seriamente este

\footnotetext{
${ }^{33}$ BRASILEIRO, Ricardo Adriano Massara. O objeto do processo civil clássico romano. Belo Horizonte: Líder, 2007, p. 127-128, onde se encontram maiores referencias. Para a aludida margem à apreciação judicial, vide, nessa mesma obra, o item 33, p. 139-149. Para uma apreciação da figuração das tábuas na crença e na prática romana: MEYER, Elizabeth A. Legitimacy and Law in the Roman World: tabulae in roman belief and practice. Cambridge: Cambridge University Press. 2004.

${ }^{34}$ D'ORS, Alvaro. Derecho privado romano. 10 ed. Pamplona: EUNSA, 2004, p. 162-165, §§ 106-108.

${ }^{35}$ KASER, Max. Direito privado romano. Trad. [da edição alemã de 1992] Samuel Rodrigues e Ferdinand Hämmerle. Lisboa: Calouste Gulbenkian, 1999, p. 456-457, § 84 I c.

${ }^{36}$ D'ORS, Alvaro. Derecho privado romano. 10 ed. Pamplona: EUNSA, 2004, p. 163, § 106.
} 
princípio, não pode ser senão oral, porque só o processo oral permite ao juiz formar um convencimento com a observação pessoal e direta do material da causa". ${ }^{37}$ Aqui, o que se entende como o cerne essencial da oralidade é o contato direto entre o órgão judicial com as pessoas suscetíveis de se fazerem fontes de informação, em suma, partes e testemunhas que depõem e são inquiridas pelo juiz em audiência. ${ }^{38} \mathrm{~A}$ essa característica essencial da oralidade se atribui o nome de imediatidade. A imediatidade, por seu turno, é garantida pela chamada identidade física do juiz, de modo que a pessoa física do juiz que colhe a prova oral em audiência deve ser a mesma pessoa física que deve julgar a causa. A esses princípios, se agregam o da concentração de grande quantidade de atos em uma ou poucas audiências, a intervalos breves - a fim de que o juiz não perca as impressões que colheu com a imediatidade -, com a consequente maior celeridade do rito, e o princípio da irrecorribilidade em separado das decisões interlocutórias, de modo a não haver interrupções no curso do processo.

\section{EXTRAORDINARIA COGNITIO E PROCESSO TARDO-ANTIGO}

O sistema da extraordinaria cognitio liga-se ao propósito imperial de Augusto de intervir diretamente na formação e na aplicação judiciaria do direito. Esse novo processo se caracteriza sobretudo pelo papel assumido pelo imperador e por seus funcionários, que se ocupavam também da investigação dos fatos e da pronúncia da sentença, monopolizando o uso da força (v.g, citações oficiais ) e podendo prescindir do impulso e da cooperação das partes, num caráter marcadamente publicístico e estatal. Afirma-se a ideia de uma administração da justiça civil não mais entregue à disponibilidade das partes e confiada à iurisdictio de magistrados eleitos por assembleias populares, mas centralizada num aparato judiciário estruturado hierarquicamente, em cujo vértice encontra-se o próprio imperador, titular de competência recursal. É esta modalidade processual a destinada a influenciar marcadamente a experiência moderna, ${ }^{39}$ a ponto de o jurista contemporâneo poder-se sentir sensivelmente familiarizado com a seguinte caracterização de D'ORS:

O procedimento deixa de ser ao ar livre e se desenvolve em ambientes fechados; o juiz, que representa a autoridade e poder do Imperador, manifesta-se como condescendente para escutar os que pedem justiça; aparece a palavra audientia. Contra as sentenças de juízes inferiores pode-

\footnotetext{
${ }^{37}$ CHIOVENDA, Giuseppe. La idea romana en el proceso civil moderno. In: Ensayos de derecho procesal civil. v. I. Trad. Santiago Sentís Melendo. Buenos Aires: EJEA/Bosch, 1949, p. 363.

${ }^{38}$ BARBOSA MOREIRA, José Carlos. O processo civil brasileiro: uma apresentação. In: BARBOSA MOREIRA. Temas de direito processual: quinta série. 2 ed. São Paulo: Saraiva, 1994, p. 4.

${ }^{39}$ Para todo o conteúdo do parágrafo, até o momento: STOLFI, Emanuele. Il processo civile. In: SCHIAVONE, Aldo. Diritto privato romano: un profile storico. 2 ed. [s/l]: Einaudi, 2010, p. 79, 150-153.
} 
se apelar aos juízes superiores. A tramitação se faz preferencialmente escrita e protocolizada; são devidos (legalmente desde meados do século IV) honorários (sportulae) para os oficiais judiciais (exsecutores), que adquirem importância em toda a marcha do processo. A Justiça se faz cara; as despesas processuais e o pagamento de juros [aparentemente introduzidos originariamente a favor do Fisco] podem agravar a condenação do demandado.

$\mathrm{Na}$ época pós-clássica, o juiz pode produzir livremente as provas que estime necessárias (princípio "inquisitivo": plena inquisitio), mas se vê limitado na respectiva valoração pelas preferencias legais (princípio da "prova taxada"): o testemunho único é rechaçado, conforme a tradição judaico-cristã, e o documento, ao contrário, adquire maior importância, assim como toda a problemática relativa à sua falsificação. Se estabelece também um sistema de presunções legais; contra elas cabe às vezes uma prova negadora do fato presumido (presunções "iuris tantum”), mas outras vezes, não (presunções “iures et de iure”).

Sobre a prova documental, o autor sublinha que "distinguem-se os protocolos (acta, gesta), os documentos notariais e os privados". Destaca igualmente que "muitos documentos não são simplesmente probatórios, senão a causa dos direitos que declaram, ou seja, constitutivos." 40

As características acima apontadas acentuaram-se com o passar dos séculos, em conexão, por um lado, com o reforço do caráter autocrático do Império e, por outro, com a mudança de eixo do poder político para o oriente, sendo uma característica comum a todo o mundo jurídico tardo-antigo, sensivelmente marcado pela prática helênica, a assunção de uma maior importância pelo elemento escrito comparativamente à havida no passado. ${ }^{41}$

Aqui estão lançadas as bases para o que se caracterizou posteriormente como o modelo processual da escritura. A relevância assumida pelo escrito no processo justinianeu foi adaptada pelo processo italiano-canônico da Idade Média, espalhou-se para todos os países da Europa continental. ${ }^{42}$. Em contrapartida à noção dogmática de oralidade, a qualificação dogmática do sistema da escritura, antes de dizer respeito à forma da prática dos atos processuais, baseia-se na ideia de que o juiz deve julgar a causa com apoio apenas em escritos, sem contato direto com as partes, testemunhas ou peritos.

\footnotetext{
${ }^{40}$ D'ORS, Alvaro. Derecho privado romano. 10 ed. Pamplona: EUNSA, 2004, p. 184-185, § 127 - o trecho entre colchetes é conteúdo de uma nota de pé de página do próprio autor. No direito brasileiro, essa modalidade de documentos é conhecida como documento integrante da substância do ato (artigo 406 do Código de Processo Civil).

${ }^{41}$ STOLFI, Emanuele. Il processo civile. In: SCHIAVONE, Aldo. Diritto privato romano: un profile storico. 2 ed. [s/1]: Einaudi, 2010, p. 79, 153-155.

${ }^{42}$ CAPPELLETTI, Mauro. O processo civil no direito comparado. Trad. Hiltomar Martins Oliveira. Belo Horizonte: Líder, 2001, p. 41.
} 


\section{CONCLUSÃO}

Tanto os elementos da oralidade como o da escritura apresentam-se no processo privado romano. Num primeiro momento, a restrição do letramento a elites diminutas, aliada a uma política de privatividade do escrito ao colégio sacerdotal, mantiveram o processo romano mais antigo das legis actiones com um caráter acentuadamente oral. A expansão peninsular romana, com o aumento do contato com outras populações itálicas e não itálicas e a transferência do eixo econômico de uma matriz agrícola e pastoril para uma matriz comercial forçaram uma modificação do sistema processual, com abertura ao reconhecimento de novos direitos. Nesse novo sistema de resolução de litígios privados do processo formular, o elemento oral ainda era prevalente, notadamente nos elementos probatórios e na sua livre apreciação pelo juiz característica fundamental do que posteriormente se designou por modelo do processo oral -, apesar da existência de um importante elemento escrito, consubstanciado na própria fórmula, que consistia no próprio programa processual a que se submetiam as partes e o juiz privado. Além disso, era um processo que se desenvolvia em público. No processo da cognição extraordinária acentua-se o caráter publicístico e estatal da resolução de litígios, ocorrida em ambientes fechados e com uma crescente maior importância do elemento escrito, seja na própria forma a ser exigida para postura válida dos atos processuais, seja pela maior importância atribuída aos documentos como meios probatórios - e aqui o gérmen do que posteriormente se caracterizou como modelo de processo escrito.

\section{BIBLIOGRAFIA}

BARBOSA MOREIRA, José Carlos. O processo civil brasileiro: uma apresentação. In: BARBOSA MOREIRA. Temas de direito processual: quinta série. 2 ed. São Paulo: Saraiva, 1994.

BETTI, Emilio. Processo civile: diritto romano. In: AZARA, Antonio e EULA, Ernesto (Dir.). Novissimo digesto italiano. v. XIII. Torino: Utet, 1966.

BRASILEIRO, Ricardo Adriano Massara. O objeto do processo civil clássico romano. Belo Horizonte: Líder, 2007, p. 112.

CAPPELLETTI, Mauro. O processo civil no direito comparado. Trad. Hiltomar Martins Oliveira. Belo Horizonte: Líder, 2001, p. 41. 
CHIOVENDA, Giuseppe. Instituições de direito processual civil. v. III. Trad. J. Guimarães Menegale (da 2a . ed. italiana). São Paulo: Saraiva, 1945.

La idea romana en el proceso civil moderno. In: Ensayos de derecho procesal civil. v. I. Trad. [da ed. italiana de 1930, acrescida de artigos avulsos] Santiago Sentís Melendo. Buenos Aires: EJEA/Bosch, 1949.

CITRONI, M., CONSOlinO, F. E., LABATE, M., NARDUCCI, E. Literatura de Roma Antiga. Trad. Margarida Miranda e Isaías Hipólito. Rev. trad. Walter de Souza Medeiros. Lisboa: Fundação Calouste Gulbenkian, 2006.

CLAVERO, Bartolome. Institucion historica del derecho. Madrid: Marcial Pons, 1992.

CORRÊA, Alexandre; SCIASCIA, Gaetano. Manual de direito romano. 6 ed. São Paulo: RT, 1988.

CORREIA, Alexandre e SCIASCIA, GAETANO. Manual de direito romano: Institutas de Gaio e Justiniano vertidas para o português, em confronto com o texto latino. v. II. São Paulo: Saraiva, 1951.

Dicionário de latim-português. 2 ed. Porto: Porto Editora, 2001 [não há indicação de autoria].

D'ORS, Alvaro. Derecho privado romano. 10 ed. Pamplona: EUNSA, 2004.

JAUERNIG, Othmar. Direito processual civil. Trad. F. Silveira Ramos [da 25a. ed. alemã, refundida, da obra criada por Friedrich Lent]. Coimbra: Almedina, 2002.

JUSTINIANO. Digesto de Justiniano, liber primus: introdução ao direito romano. Trad. Hélcio Maciel França [edição bilíngüe]. 3 ed. São Paulo: RT; Osasco: UNIFIEO, 2005.

KASER, Max. Direito privado romano. Trad. [da edição alemã de 1992] Samuel Rodrigues e Ferdinand Hämmerle. Lisboa: Calouste Gulbenkian, 1999.

LÉVY, Pierre. As tecnologias da inteligência. Tradução de Carlos Irineu da Costa. Rio de Janeiro: Ed. 34, 1993.

LOSANO, Mario G. Os grandes sistemas jurídicos: introdução aos sistemas europeus e extraeuropeus. Trad. Marcela Varejão. Rev. trad. Silvana Cobucci Leite. São Paulo: Martins Fontes, 2007.

MEIRA, Sílvio A. B. A lei das XII tábuas: fonte do direito público e privado. 3 ed. Rio de Janeiro: Forense, 1972, p 169.

MEYER, Elizabeth A. Legitimacy and Law in the Roman World: tabulae in roman belief and practice. Cambridge: Cambridge University Press. 2004.

MILLAR, Robert Wyness. Los principios formativos del procedimento civil. Trad. Catalina Grossman. Buenos Aires: Ediar, 1945.

PUGLIESE, Giovanni, con la collaborazione di SITZIA, Francesco, e VACCA, Letizia. Istituzioni di dirito romano. 3 ed. Torino: Giappichelli, 1991. 
STOLFI, Emanuele. Il processo civile. In: SCHIAVONE, Aldo. Diritto privato romano: un profile storico. 2 ed. [s/l]: Einaudi, 2010.

VILLEY, Michel. Direito romano. Trad. Fernando Couto. Porto: Rés [s.d]. 